\title{
EL NIETZSCHE DE WALTER KAUFMANN \\ Walter Kaufmann's Nietzsche
}

Axel Pérez Trujillo

Universidad Autónoma de Madrid

RESUMEN: El artículo se presenta como una invitación a la relectura de las cuestiones más importantes dentro del estudio monográfico de Walter Kaufmann Nietzsche: Philosopher, Psychologist, Antichrist. Muchas de sus interpretaciones han esclarecido la comprensión del pensamiento de Nietzsche, estableciendo fuertes contrastes con la exégesis de filósofos tan destacados como Deleuze, Jaspers y Heidegger. Dado el interés del libro de Kaufmann en los estudios nietzscheanos, se ha intentado contextualizar e integrar lo que escribió sobre Nietzsche dentro de las fronteras marcadas por otras de sus publicaciones. Como escritor prolífico y lúcido, Kaufmann merece un análisis detallado de sus trabajos sobre Nietzsche.

Palabras clave: Übermensch - Sócrates - monismo dialéctico - cultura

ABstRACT: The article presents itself as an invitation to review some of the most significant themes woven in Walter Kaufmann's monograph Nietzsche: Philosopher, Psychologist, Antichrist. Many of his insights have thrown light on Nietzsche's thought, as well as established sharp contrasts with the interpretations of distinguished philosophers such as Deleuze, Jaspers, and Heidegger. Given the interest of Kaufmann's book for Nietzschean studies, an attempt has been made to contextualize and integrate what he wrote about Nietzsche within the bounds of his other published work. As prolific and lucid writer, Kaufmann deserves a detailed account of his work regarding Nietzsche.

Keywords: Übermensch - Socrates - Dialectical Monism - Culture

Rumiar lo escrito por Nietzsche es mucho más que leer detenidamente. No se trata de saborear las palabras sino de digerirlas, de hacerlas sangre. Su estilo tiene un tempo propio, un ritmo decadente que trata de superarse a sí mismo. Un estilo cuyos tonos declinan y vuelven a remontarse in crescendo. Desespera a lectores despreocupados que se dejan llevar por el vaivén de su estilo sin apreciar el tempo que lo conduce. También sus lectores atentos quedan enredados en los diversos tonos que suenan como campanas en sus textos. Buscar lo que dijo Nietzsche exige adquirir una ligereza de pies para poder seguirle los pasos al jovial danzarín. Para esto no basta conocer el lenguaje, no basta conocer el significado de los términos fuera de su contexto. Es menester «hacerse con el autor». ${ }^{1}$ Precisamente,

1. F. Nietzsche, «Introduction», en Genealogy of morals, ed. de W. Kaufmann, New York: Vintage, 1969 , p. 5. 
Walter Kaufmann ofrece algunas claves para acceder a la pluralidad estilística de Nietzsche, para evitar malinterpretarle. Su Nietzsche: Philosopher, Psychologist, Antichrist (1950) brinda unas pistas para articular el pensamiento de Nietzsche, desde su juventud hasta las últimas obras publicadas. Y es que su estudio monográfico no es sino un intento de refutar la idea de que Nietzsche «carecía de una filosofía coherente $»^{2}$. Es la apuesta arriesgada de buscar un hilo conductor para mostrar su pensamiento como un tejido vivo y no contradictorio. Cuando ni siquiera existía una edición crítica de las obras de Nietzsche, Kaufmann se atrevió a presentar la obra del filósofo alemán a un público anglosajón reticente a escuchar cualquier cosa relacionada con la Alemania de la época. No sólo logró calar su mensaje en los círculos intelectuales de Princeton, sino también legó a los estudiosos una magnífica investigación de la filosofía de Nietzsche.

Una de las claves más llamativas que señala es la influencia de la figura de Sócrates en la obra y pensamiento de Nietzsche. Bajo la figura del «Sócrates artístico", Kaufmann profundizará sobre un asunto que ha tenido poca trascendencia más allá del mundo anglosajón, pero que resulta fascinante e imprescindible para aquellos lectores que no se cansan de repasar los escritos del pensador alemán. Se trata del supuesto método dialéctico que habría desarrollado Nietzsche. La monografía de Kaufmann lanza la tesis provocativa de que el autor de Zur Genealogie der Moral es mucho más dialéctico de lo que parece. Semejante propuesta entabla una abierta polémica con el brillante estudio de Gilles Deleuze, Nietzsche et la philosophie, en el cual se destaca más bien «el carácter resueltamente antidialéctico de la filosofía de Nietzsche» ${ }^{3}$. A pesar de este notable choque entre dos gigantes de la exégesis nietzscheana, lo cierto es que Kaufmann no menciona el libro de Deleuze en la extensa bibliografía que completa su monografía, y ello a pesar de que disfrutó de una tercera (1968) y cuarta (1974) ediciones revisadas minuciosamente. Aunque los dos exégetas presentan interpretaciones aparentemente dispares, no dejan de enriquecer la lectura y comprensión de la obra de Nietzsche. Seguramente que de la controversia sobre el papel de la dialéctica en Nietzsche, surja un fecundo diálogo: Un diálogo que ningún estudioso puede perderse, ya que tanto Kaufmann como Deleuze son hábiles maestros cuyos libros se han convertido en hitos de la investigación nietzscheana.

Al margen de la polémica entre ambos autores, la insistencia de Kaufmann por señalar el método dialéctico de Nietzsche busca establecer una sugerente comparación con Hegel. No se pierda de vista el hecho de que Kaufmann haya escrito también un estudio monográfico sobre Hegel, además de haber traducido varias de sus obras al inglés ${ }^{4}$. Pues bien, aún admitiendo que existen diferencias significativas entre Hegel y Nietzsche, afirmará lo siguiente de este último: el desarrollo de la voluntad de poder fue una nueva respuesta al problema del valor que había quedado irresuelto en la filosofía del joven Nietzsche, una respuesta que subsume el dualismo de la metafísica de artista en un «monismo dialéctico» ${ }^{5}$.

2. W. Kaufmann, Nietzsche: Philosopher, Psychologist, Antichrist, Princeton: Princeton University Press, 1974, p. 3.

3. G. Deleuze, Nietzsche y la filosofía, trad. de C. Artal, Barcelona: Anagrama, 2002, p. 17.

4. Cf. W. Kaufmann, Hegel: Reinterpretation, Texts, and Commentary, 2 vols., Garden City (NY): Doubleday, 1965.

5. W. Kaufmann, Nietzsche: Philosopher, Psychologist, Antichrist, cit., p. 235. 
Y todo ello sin olvidar que Sócrates representa un tipo de hombre que reúne ese afán dialéctico recurrente en toda la obra de Nietzsche hasta llegar a Ecce homo. Si bien las propuestas de Kaufmann no dejan de ser perspicaces y sorprendentes, la claridad de su argumentación es sin duda uno de los puntos fuertes de su monografía. Una y otra vez insiste en ubicar los pasajes citados, despejando posibles ambigüedades en la interpretación. Su intención no es pasar a Nietzsche por un lecho procrústeo, sino ofrecer una recuperación que no retuerza forzosamente su pensamiento ${ }^{6}$. De ahí que merezca la pena repasar algunos puntos de su Nietzsche, aunque sea de manera modesta, pues cuanto menos servirá para recuperar una interpretación atrevida y reveladora en muchos sentidos.

Tras una breve introducción a la vida de Nietzsche, la monografía arranca con una explicación del modo de proceder que se despliega en sus escritos. Pretende mostrar el método que sigue Nietzsche. Un método que le comprometerá a defender diversas posiciones en el transcurso de sus obras y que explica sus mudanzas de piel. Y es que afrontar su pensamiento es encontrarse no sólo con aforismos. Parte de sus escritos preservan una estructura ensayística cubierta en algunos casos por una densidad poética y figurativa que hace muy difícil siquiera aproximarse a ellos. Pero por debajo del cambiante estilo, yace su pathos interno. Dar cuenta de esa vivencia interna es un primer paso para estar a la altura de escuchar lo que quiere comunicar. Por ello, reconstruir el pensamiento de Nietzsche exige como primera tarea mostrar el hilo conductor que permanece por debajo de los oleajes estilísticos.

Tal vez pueda realizarse tal restauración como si su filosofía fuese un conjunto de escombros, pero Kaufmann insiste en que se trata de articular el «estilo monadológico» de sus aforismos con el resto de su obra ${ }^{7}$. Los aforismos son mónadas en la medida en que subsisten por sí, pero a su vez salpican a los demás aforismos. Cada uno condiciona el significado de los demás. De ahí que descontextualizar a un aforismo sea correr el riesgo de una mala interpretación, cuestión que parece no haber preocupado durante largo tiempo a célebres exégetas de Nietzsche. Ir en busca de contradicciones tampoco sirve a la comprensión. Diseccionar su pensamiento es perder de vista su continuidad, su desarrollo. Citar al margen del contexto para después señalar puntos de conflicto tiene poco mérito, pues tal recurso puede emplearse sobre cualquier pensador sin avanzar en su comprensión. Kaufmann está pensando en contra de dos autores destacados en la larga lista de exégetas nietzscheanos: Jaspers y Heidegger. Aunque no les mencione explícitamente en su Nietzsche, en uno de sus estudios sobre el existencialismo explica que tanto el uno como el otro apoyan sus lecturas en muchas citas que «dependen de hacer caso omiso del contexto» ${ }^{8}$. Una vez más, puede apreciarse cómo Kaufmann se enfrenta a las interpretaciones predominantes de su época.

Ahora bien, lo característico del proceder de Nietzsche es que rechaza toda pretensión de sistematicidad. Todo edificio filosófico que pretenda cerrarse sobre sí, que aspire a ser un sistema, presupone una base sobre la que no se cues-

6. Ibid., p. xiii.

7. Ibid., p. 75

8. W. Kaufmann, Existentialism from Dostoevsky to Sartre, New York: Meridian Books, 1958, p. 33. 
tiona. No recae sobre sus presupuestos para interrogar su verdad, los acepta sin más. En cierto modo, tales filosofías sistemáticas carecen de sinceridad, pues no se comprometen a probar sus premisas. Conducido por su insistencia en la veracidad, Nietzsche tiende a perforar y problematizar esas premisas comúnmente aceptadas, al igual que Sócrates ${ }^{9}$. Similar a la mayéutica, se arranca de un problema para desplazarse de manera «dialéctica» hacia atrás, buscando el origen de las creencias básicas ${ }^{10}$. Así, la genealogía se despliega a la manera de la dialéctica socrática. Y aquí aprovecha Kaufmann para introducir la afinidad muy llamativa entre Hegel y Nietzsche. Mientras el primero es un filósofo que consiguió ser "tanto un filósofo dialéctico como un constructor de sistemas», Nietzsche preservó su método para cuestionar todo supuesto no probado ${ }^{11}$. No obstante, el punto de contacto que sugiere Kaufmann sigue estando ahí: Nietzsche desarrolla un proceder dialéctico, no solamente durante su juventud sino en toda su obra. Un método que muestra la influencia de Sócrates en su pensamiento. Hasta qué punto sea acertada semejante afirmación es un asunto pendiente de la valoración y análisis del papel de lo negativo en el conjunto de la obra de Nietzsche, como tal vez insistiría Deleuze. Si bien algunos momentos de la argumentación del joven Nietzsche parecen efectivamente moverse por momentos dialécticos, no está tan claro dónde pueda encontrarse semejante método en las obras de madurez.

Según Kaufmann, el compromiso metódico que despliega Nietzsche insta a pensar cada aforismo como un «experimento", tanto en su significado científico como en su "cualidad existencial» ${ }^{12}$. Los aforismos constituyen una serie de ensayos que se realizan en su laboratorio, como tanteos para ver qué resultados se obtienen. Pero también son respuestas a ciertos problemas, respuestas cuya validez se mide a través de la posibilidad de vivir de acuerdo con ellas. Los problemas no son, pues, triviales. Uno arriesga su vida en cada experimento para apreciar sus resultados. Así, para Nietzsche, "ciencia y vida ya no están enteramente separadas; ciencia y filosofía son un estilo de vida» ${ }^{13}$. Compárese con la lectura que brinda Alexander Nehamas, quien trabajó bajo la tutela de Kaufmann durante una breve estancia en Princeton: su lectura insiste en que el perspectivismo de Nietzsche no es tanto una teoría del conocimiento como un enfoque que arranca del tipo de vida que lleva a cabo cada persona ${ }^{14}$. Es decir, los planteamientos del pensador alemán se hayan estrechamente ligados a la vida misma, no pueden ser aislados de lo vital. Se juegan en ese mismo plano. No obstante, lo cierto es que ambos exégetas difieren sobre ciertos puntos en sus interpretaciones, especialmente en lo que concierne al papel del aforismo dentro de la obra de Nietzsche. A pesar de ello, coinciden en llamar la atención sobre la importancia del estilo de Nietzsche y el papel de Sócrates. Y tal vez se deba a que los dos intérpretes admiten una gran estima por la escritura de Nietzsche. Kaufmann llega incluso a afirmar en su antología de textos de Nietzsche que éste tal vez escribía demasia-

9. W. Kaufmann, Nietzsche: Philosopher, Psychologist, Antichrist, cit., pp. 82-83.

10. Ibid., p. 83.

11. Ibid.

12. Ibid., p. 89.

13. Ibid., p. 90

14. A. Nehamas, Nietzsche, Life as Literature, Cambridge: Harvard University Press, 1985, p. 73. 
do bien como filósofo ${ }^{15}$. Es más, en uno de sus estudios menos conocidos, From Shakespeare to Existentialism (1959), Kaufmann trata de vincular a Nietzsche con la tradición literaria que arranca desde Shakespeare y pasa por Goethe y Rilke ${ }^{16}$. No obstante, la monografía afirma que el estilo aforístico es el vehículo a través del cuál Nietzsche se expresa más profundamente: es el corazón que bombea la sangre de su método dialéctico. De ahí que ese método dialéctico y genealógico, según Kaufmann, sea una unión entre ciencia y filosofía que apunte hacia la figura del «Sócrates artístico» como posible realización.

Dado que el proceder genealógico no pretende en absoluto ser sistemático, es preciso despejar el siguiente interrogante: ¿Acaso la muerte de Dios no es un presupuesto del cual arranca toda la filosofía de Nietzsche? ¿Acaso no es tal acontecimiento la base de su método? Kaufmann insiste: responder de manera afirmativa a tal pregunta sería cometer un error. La muerte de Dios no es una premisa del método adoptado por Nietzsche, no es el paso previo para poner en marcha la genealogía. Más bien es un diagnóstico de la sociedad que da cuenta del advenimiento de la «devaluación» de los valores» ${ }^{17}$. Al sospechar de toda creencia, Nietzsche se percata del estrecho vínculo que existe entre el valor del ser humano y la existencia de Dios. Recuérdese que nuestro autor no sólo afirma que «dios ha muerto» sino también que «le hemos matado - tú y yo». Es decir, la genealogía descubre el nihilismo que ha contagiado a la humanidad bajo el ideal ascético. El problema del valor, «escapar al nihilismo", será una de las preocupaciones centrales en el pensamiento de Nietzsche. Buscar una salida al nihilismo pasa, sin embargo, por acelerar esa «devaluación» a través de su crítica dialéctica para despejar los valores asumidos y permitir el establecimiento de nuevos valores. Pero esos «filósofos verdaderos» que asumirán el papel de legisladores aún están por llegar. Lo máximo a lo que pueden aspirar los filósofos del presente es a ser médicos, a intervenir quirúrgicamente e infiltrar los valores predominantes. Una vez más, Kaufmann señala la afinidad entre Sócrates y la tarea que se propone realizar Nietzsche. Ambos son cirujanos de la moral, ofrecen diagnósticos para en un futuro curar a sus pacientes. Si sus diagnósticos parecen esconder alguna prescripción, no por ello se ha de pensar que Nietzsche ofrece nuevos valores. Kaufmann insiste en que no se trata de una sustitución de valores sino más bien de una «re-evaluación» de todos los valores. No hay siquiera una inversión de valores. El método dialéctico no supone una tarea positiva, una legislación de nuevos valores, pues su meta es diagnosticar, descubrir «el brote canceroso». Solamente puede entenderse de manera positiva en la medida en que «niega la negación»" ${ }^{18}$, contradice los valores predominantes que han sumido a Occidente en el nihilismo. Ahí radica su inmoralismo, su crítica subterránea de la moral. Además, Nietzsche no quiso fundar una nueva fe. A pesar de la tentación de dejar a un lado su método crítico en Also sprach Zarathustra, no se trataba de crear una escuela de seguidores. Acabó por resistir tal tentación,

15. W. Kaufmann, «Introduction», en The portable Nietzsche, ed. de W. Kaufmann, New York: Penguin Books, 1976, p. 1.

16. W. Kaufmann, «Art, Tradition, and Truth», en From Shakespeare to Existentialism, Princeton: Princeton University Press, 1980, p. 241.

17. W. Kaufmann, Nietzsche: Philosopher, Psychologist, Antichrist, cit., p. 101.

18. Ibid., p. 112. 
abandonando su obra capital y continuando con su compromiso metodológico. No quería «creyentes» sino lectores críticos y veraces. A pesar de todo, mantuvo su crítica hasta el final sin caer en la fundación de un nuevo sistema o religión: el «Nietzsche-Sócrates supera al Nietzsche-Wagner» ${ }^{19}$.

Uno de los momentos más brillantes del Nietzsche de Kaufmann es su interpretación sobre la etapa de juventud. En ella, se muestra cómo muchos de los grandes temas desarrollados posteriormente se encuentran anunciados tanto en Die Geburt der Tragödie como en el ciclo intempestivo. Cabe insistir sobre la lectura muy aguda que brinda Kaufmann de este periodo. Bien merece la pena repasar su Tragedy and Philosophy (1968) para completar el estudio monográfico de Nietzsche, como él mismo señala ${ }^{20}$. También es de interés la atención que presta a Schopenhaner als Erzieher, señalando que supone el resultado de los planteamientos del joven Nietzsche: es ahí donde se enfrenta de lleno a las complicaciones que laten en las respuestas que había ofrecido en sus obras anteriores. Así, las propuestas que posteriormente planteará su pensamiento deben articularse teniendo en cuenta el hecho de que los «experimentos» llevados a cabo resultaron insatisfactorios ante el problema del valor. Hay tres surcos que merecen trazarse en la argumentación de Kaufmann. En primer lugar, Kaufmann indica cómo Nietzsche empieza a elaborar una concepción de la salud que entronca con la cuestión del valor. Una concepción «dialéctica» que no conseguirá articularse con la perspectiva "suprahistórica» y la noción de «cultura». En segundo lugar, Kaufmann insiste en el impacto que supone el pensamiento de Darwin. Ante la animalidad del ser humano, Nietzsche buscará un nuevo lugar donde situar a unos pocos «excelsos ejemplares». Cierto es que hay una selección, pero no se despliega como pretende el autor de On the Origin of Species. En tercer y último lugar, la concepción de la cultura en Schopenhauer als Erzieher será, según Kaufmann, el intento de ofrecer un medio para «transfigurar» la animalidad del ser humano. Y precisamente éste será el hilo conductor que servirá para consumar el pensamiento del joven Nietzsche. Estos surcos presentan un camino original hacia la comprensión de su pensamiento sin pretender fragmentarlo en diversas etapas: el despliegue de su «filosofía del poder» no es sino un desarrollo que arranca de las inconsistencias generadas en los tanteos iniciales de su pensamiento.

En las páginas de Die Geburt der Tragödie transcurre una dialéctica mucho más compleja de lo que se aprecia en una primera lectura. La relación que se establece entre Dioniso y Apolo es de especial interés, puesto que tiende a ser malinterpretada. Si bien en Der Antichrist la figura de Dioniso es central, Kaufmann hace bien en señalar que ese tipo no se identifica con aquél empleado en la obra de juventud. En esta última, el énfasis no recae sobre Dioniso, sino más bien en Apolo $^{21}$. El impulso embriagador es un elemento negativo que induce al «genio apolíneo» hacia la producción de valores estéticos. Ante el abismo en que sume lo dionisíaco, el artista se vuelca en la transfiguración de ese sufrimiento en una obra de arte. El Dioniso que se enfrenta al crucificado, en cambio, recoge en su seno esa relación dialéctica entre los dos impulsos de la metafísica de artista. La

19. Ibid., p. 117.

20. W. Kaufmann, Tragedy and Philosophy, Princeton: Princeton University Press, 1992, p. xi.

21. W. Kaufmann, Nietzsche: Philosopher, Psychologist, Antichrist, cit., p. 127. 
capacidad de transfigurar o sublimar los impulsos desmesurados será una de las piezas claves de la «filosofía del poder». Además, no ha de perderse de vista esa mudanza de piel, pues Kaufmann terminará identificando al Dioniso de madurez con el «Sócrates artístico», resaltando la actitud receptiva que se preserva con el protagonista de los diálogos platónicos.

Nótese que Kaufmann insiste en que subyace un dualismo metafísico en esta obra de juventud. Precisamente, esa distinción entre el supuesto dualismo de juventud y el monismo de madurez le servirá para articular el pensamiento de Nietzsche. Pero, ¿está justificada esa distinción? Desde luego, la metafísica de artista parece más bien inclinarse hacia un monismo que subsume ambos impulsos bajo lo «uno primordial», lo cual seguramente fuese la razón por la que Nietzsche escribiese en Ecce homo que su obra «desprende un repugnante olor hegeliano $»^{22}$. Kaufmann, no obstante, es un perspicaz lector y merece la pena señalar las claves que apoyan su tesis en Die Geburt der Tragödie. Ya en el primer parágrafo, Nietzsche insiste en describir la relación entre el impulso apolíneo y dionisíaco como la dualidad de sexos. Al igual que la oposición entre lo masculino y lo femenino, la fugaz reconciliación entre Apolo y Dioniso da lugar a la procreación, la generación de valores estéticos. Acto seguido, afirma que esa «antítesis» atañe no solamente a las «metas» sino también a los «orígenes» de ambos impulsos ${ }^{23}$. La distancia marcada, ese «abismo» entre las dos partes, hunde sus raíces en los orígenes de tanto lo apolíneo como lo dionisíaco. Y si sus orígenes son distintos, la metafísica de artista se topa con un serio problema para tratar de resolver esa antítesis. Articular ese profundo antagonismo al «uno primordial» no es tarea fácil. Tal vez por ello Nietzsche escriba con cautela al comienzo del cuarto parágrafo que su apreciación de los dos instintos le ha hecho inclinarse hacia la "conjetura metafísica» de lo «uno primordial» ${ }^{24}$. Es decir, la metafísica de artista no es una propuesta de carácter contundente, sino una hipótesis de trabajo, una propuesta que no pretende ser definitiva, que no trata de responder a las graves dificultades suscitadas por la oposición entre Apolo y Dioniso. No hay que perder de vista el carácter conjetural de la metafísica de artista, ya que pone de relieve que el texto no es una respuesta final. Más bien es un primer tanteo, un primer experimento, en el desarrollo de la genealogía.

Pues bien, la explicación que ofrece sobre esos dos impulsos en el joven Nietzsche le sirve, a su vez, para mostrar la configuración de una «concepción dialéctica de la salud»: otro de los grandes temas de madurez. La pulsión dionisíaca es semejante a una fiebre que quiebra el principio de individuación. Es un estado febril y doloroso que sólo puede sanarse mediante la transformación que realiza lo apolíneo. Kaufmann hace notar que se está concibiendo la salud como la superación de la enfermedad. La salud no es ausencia de infección, sino es la capacidad de sobrellevar el malestar ${ }^{25}$. Esta misma concepción hará eco en Morgenröte. La pregunta por la jovialidad griega se entronca directamente con la dialéctica de la salud desplegada. Nietzsche se pregunta cómo un pueblo que sufrió tanto pudo generar valores estéticos. Dicho en otras palabras, se pregunta

22. KSA VI 310.

23. KSA I 25.

24. Ibid., p. 38 .

25. W. Kaufmann, Nietzsche: Philosopher, Psychologist, Antichrist, cit., p. 131. 
cómo un pueblo tan enfermo pudo transfigurarse, pudo curarse. La tragedia es ese «consuelo metafísico» que capacitó a los griegos para superar su infección. Por ello, la cuestión del valor, entendida en términos estéticos en esta primera obra, se halla entrelazada con la dialéctica de la salud en la medida en que la «belleza es percibida como la respuesta de un organismo fundamentalmente sano ante el desafío de la enfermedad ${ }^{26}$.

En Vom Nutzen und Nachteil der Historie für das Leben, Nietzsche volverá a centrarse sobre la cuestión de la salud, sólo que a través del debate sobre lo «histórico»y «ahistórico». Aquí la vida solamente puede reproducirse en un equilibrio entre la memoria y el olvido. Un exceso de cualquiera de esos elementos supone arrebatarle el aliento a la vida. No obstante, la dialéctica de la salud parece quebrarse en el momento en que se introduce lo "suprahistórico", una perspectiva que está por encima de la historia. Una óptica que busca los tipos en la historia, organizando así el aparente caos. A pesar de los problemas que suscita en los esquemas de la enfermedad y salud, será una propuesta que acompañará a Nietzsche el resto del recorrido intelectual. De hecho, tal punto de mira ya está patente en Die Geburt der Tragödie, pues tanto Apolo como Dioniso son tipos. Mirar por encima de la historia, buscando una manera de organizar el aparente caos es mantener una «auto-disciplina», según Kaufmann. Una autodisciplina característica de la «filosofía del poder» que elabora Nietzsche, pues el rasgo principal de la voluntad de poder no es sino superarse a sí misma o, dicho de otro modo, «sublimar» el caos de impulsos. No obstante, el problema sobre como generar valores ante la infección que sufre la humanidad sigue siendo problemático. De hecho, el tratamiento de la cultura supone un nuevo intento de brindar una solución satisfactoria. Y es en este punto donde comienza Schopenhaner als Erzieher que, como se ha señalado, es la «consumación» de la filosofía del joven Nietzsche según Kaufmann.

La teoría de Darwin suponía otra amenaza al valor de lo humano, pues si el ser humano puede reducirse a un animal, no importa cuánto avance la historia ya que no le lleva en un camino ascendiente hacia su autorrealización, hacia el establecimiento y aumento de su valor. No hay un progreso en esa Selección Natural. A pesar del aparente éxito de la especie humana, no cabe hablar de que su valor sea mayor en el presente que hace unos milenios. En la segunda obra del ciclo intempestivo se propuso una primera respuesta ante la animalidad de los seres humanos, insistiendo en que son unos «excelsos ejemplares» los que otorgan sentido a la humanidad. Estos genios se elevan por encima de las masas al transfigurar su naturaleza animal, al generar una nueva naturaleza: la cultura. Superar la animalidad es transformar esa primera naturaleza heredada. De ahí que Nietzsche «despertase de su sueño dogmático gracias a Darwin» ${ }^{27}$. Es más, uno de sus colegas durante la estancia en Basilea fue el médico Ludwig Rütimeyer, quien traspasó sus investigaciones al estudio de la naturaleza desde disciplinas tales como la biología o la geología ${ }^{28}$. No ha de sorprender, pues, que Nietzsche desarrollase un interés cada vez mayor sobre los avances de la ciencias naturales. Sin embargo, no queda claro el origen de esa fuerza transfor-

26. Ibid., p. 132.

27. Ibid., p. 167.

28. C. Janz, Friedrich Nietzsche, trad. de J. Muñoz, Madrid: Alianza, 1981, vol. II, p. 43. 
madora que superaría la animalidad de unos pocos hombres. Y esto es así porque Apolo parece ser una fuerza supernatural, mientras que a Nietzsche le interesa articular una teoría del valor naturalista que corra pareja con la dialéctica de la salud $^{29}$. Así, su insistencia en buscar un criterio naturalista para el valor termina por estrellarse con la metafísica de artista. El experimento que se avanzó en Die Geburt der Tragödie resulta no cumplir las exigencias del método que guía a Nietzsche, consumiéndose en Schopenhauer als Erzieher.

Llegado a este punto, la monografía se ocupa de la «filosofía del poder», analizando en detalle la voluntad de poder. Ésta se propone como un nuevo experimento ante el aparente fracaso del dualismo de la metafísica de artista. Toda moral es reconducida a esta fuerza original, a esta tendencia a la superación de sí. Ya en Morgenröte aparecen algunos elementos que indican el camino hacia el descubrimiento de la voluntad de poder. Es importante reparar en el peso que otorga Kaufmann a la caracterización de ésta como «auto-superación». Su argumentación se fija a partir de ese rasgo de la voluntad de poder para tratar de aclarar su articulación no solamente con las doctrinas del eterno retorno y el Übermensch, sino también con la dialéctica entre lo apolíneo y dionisíaco. No obstante, el criterio de demarcación de la moral que se establece será la tendencia a la superación de sí. Ser moral es aspirar a superar los impulsos, a mandar sobre las pasiones. Ese control de los impulsos es una manifestación de la voluntad de poder. Pero el monismo que supone conlleva dos problemas que han de aclararse. En primer lugar, hay que demostrar cómo los impulsos pueden ser superados. Hay que explicar si el proceso de superación pasa por una supresión de las pulsiones, o si más bien se trata de subsumirlas. La cuestión gira en torno al aspecto «psicológico» de la superación de sí. En segundo y último lugar, hay que indagar sobre la compatibilidad del monismo de la voluntad de poder con su tendencia a la autosuperación. Al haber solamente una fuerza o tendencia, ¿cómo dar cuenta de la superación de sí cuando ésta parece exigir la presencia de dos fuerzas en pugna? Aquí se juega la posibilidad misma del monismo que propone Nietzsche. Y precisamente la respuesta que ofrecerá Kaufmann ahondará sobre las afinidades con Hegel y lanzará la tesis ya adelantada del «monismo dialéctico». Si bien su interpretación parece arriesgada, de lo que no cabe dudar es de la lucidez con la que es capaz de entretejer la «filosofía del poder», tarea que resulta un verdadero rompecabezas a los lectores más atentos.

La clave para comprender el proceso psicológico a través del cual se realiza la superación de sí se encuentra en el primer aforismo de Menschliches, Allzumenschliches. Es ahí donde Nietzsche expresa por vez primera la idea de que la «química» de los sentimientos morales se despliega mediante la «sublimación». Recuérdese en que una de las mayores dificultades con las que se estrellaba la filosofía de juventud era el dar cuenta del origen de lo apolíneo. Mantener a esa fuerza amarrada a un criterio naturalista de valores fue uno de los puntos en los que fracasó ese experimento. Al avanzar la noción de sublimación, se elabora una nueva respuesta. La transfiguración de la naturaleza dada encuentra en la sublimación una solución tentativa. No se trata de «extirpar» o rechazar los impulsos, a la manera de un asceta, sino de mandar sobre ellos. Es menester no

29. W. Kaufmann, Nietzsche: Philosopher, Psychologist, Antichrist, cit., p. 170. 
perder de vista este asunto, pues cobrará intensidad a medida que se despliegue la «filosofía del poder» en el pensamiento de Nietzsche.

Una vez argumentado el primer interrogante, Kaufmann se dirige a la cuestión central de su Nietzsche: el «monismo dialéctico» que recoge la doctrina de la voluntad de poder. Para dar cuenta de la posibilidad de la superación de sí dentro del «monismo metafísico» ${ }^{30}$ de Nietzsche, es menester arrancar del supuesto irracionalismo que late en su filosofía de madurez. El compromiso metodológico le lleva a cuestionar el lugar privilegiado de la razón y, a su vez, sus estudios empíricos apuntan a la voluntad de poder como la tendencia que subyace a toda acción. Tal vez pueda hablarse de una posición irracionalista en tanto que todo comportamiento es reconducido a ese ímpetu que busca superarse una y otra vez. Pero sería equivocado reducir la «filosofía del poder» a irracionalismo sin más, pues la razón no se disuelve del todo en la voluntad de poder. Es la razón la que somete a los impulsos. El hombre racional ejercerá su poder al sublimar sus pulsiones. Así, «la voluntad de poder no es ni idéntica ni opuesta a la razón, sino potencialmente racional $\aleph^{31}$. Tanto la razón como los impulsos son manifestaciones de ese principio básico. La relación dialéctica que se producirá entre ambos recoge el dualismo de Apolo y Dioniso en Die Geburt der Tragödie. Ese dualismo será, no obstante, superado en la medida en que se reconduce al monismo de la voluntad de poder. Aún así, la distinción entre razón y pasión permite poner en marcha la superación de sí que, según Kaufmann, mejor caracteriza a la voluntad de poder. Aquí cabe ahora una comparación detallada entre el Aufheben hegeliano y el Sublimieren que propone Nietzsche. Una comparación en la que es preciso resaltar el hecho de que Nietzsche insiste en el elemento negativo, en el dolor, sufrimiento y crueldad que conlleva la superación de sí. La propuesta de Nietzsche sería una llamada al perfeccionamiento de uno mismo, aspirando a trascender las limitaciones propias. A pesar del dolor y sufrimiento, a pesar de la enfermedad que se padece, hay que buscar su superación en cada instante. La salud será la capacidad de aguantar la infección que se padece. No solamente se resuelven los problemas que suponía el origen de lo apolíneo sino también se encaja con la dialéctica de la salud anunciada en la filosofía de juventud. Queda ahora por articular la voluntad de poder a la cuestión del eterno retorno y el Übermensch.

El Übermensch debe entenderse principalmente bajo el prisma de la superación de sí. Es aquel «hombre que se ha superado a sí mismo» ${ }^{32}$. Los seres humanos se encuentran tendidos sobre un abismo, tambaleando en un «apuro ontológico» ${ }^{33}$. A un extremo de la cuerda se halla su animalidad, mientras que al otro está el Übermensch. Llegar a ese tipo de hombre pasa por la perfección de sí, por la sublimación de los impulsos. El único camino para aspirar a esa meta exige transformar su naturaleza, su animalidad. Solamente unos pocos alcanzaran a realizar esa transfiguración. Ese Übermensch queda recogido en la figura de Goethe, pues éste es a los ojos Nietzsche uno de los pocos hombres que ha logrado la autodisciplina ${ }^{34}$. Consiguió organizar el caos de sus impulsos, a la

30. Ibid., p. 239.

31. Ibid., p. 234.

32. Ibid., p. 309

33. Ibid., p. 310.

34. Ibid., p. 316. 
manera en que la óptica «suprahistórica» se ocupaba de organizar la historia en tipos. Y precisamente, será esa perspectiva que se anunciaba en Von Nutzen und Nachteil der Historie für das Leben el germen de la doctrina del eterno retorno. Se trata de situarse por encima de la historia, más allá del pasado y el futuro. En esa obra de juventud, Nietzsche rechazaba la noción de progreso, optando por ver en unos pocos «excelsos ejemplares» el valor de la humanidad. Pues bien, el eterno retorno será una experiencia que servirá para impulsar a los fuertes hacia la perfección de sí, a aspirar al Übermensch y desear su realización eterna. Se trata de un criterio de selección de los mejores, de los sanos. De ahí que el eterno retorno sea la experiencia que presiona al ser humano a arriesgarse ante el «apuro ontológico», de otorgar valor a su vida. Además, Nietzsche concibe esa doctrina como un "punto de unión entre la ciencia y la filosofía» ${ }^{35}$, cuestión que había perseguido su método dialéctico. Tanto la interpretación cosmológica como existencial se entrecruzan en el eterno retorno. Ahora bien, ¿̇cuál es la figura que reúne y articula las preocupaciones recurrentes en su pensamiento? ¿Cómo concibe Nietzsche su propia tarea?

Tal vez la única respuesta se encuentre en Ecce homo, la culminación de su obra. No sólo es el último libro que escribió, sino también «la consumación de su filosofía ${ }^{36}$. Prestar atención a las palabras ahí fijadas es acompañarle en la travesía de su pensamiento, mirando con sus ojos. Es escuchar la exclamación de Nietzsche. iHe aquí un hombre! No un santo, sino «una nueva, una diferente imagen de la humanidad ${ }^{37}$. Ya en Die Geburt der Tragödie se vislumbraba en el porvenir a la figura de un "Sócrates artístico», un nuevo tipo de hombre. Y esa descripción de Sócrates en la que éste termina por cultivar la música quizás sea «la mejor caracterización del propio Nietzsche» ${ }^{38}$. Aquel hombre que diseccionaba e infiltraba los presupuestos morales con la dialéctica al modo de un médico se aproxima a la tarea que se propuso a sí mismo. De hecho, Sócrates arroja nueva luz sobre el método dialéctico-genealógico que atraviesa todo su pensamiento. Pero ese tipo de hombre supone mucho más. Para el joven Nietzsche, el maestro de Platón es un Lebensphilosoph ${ }^{39}$, un filósofo de la vida. No es baladí el que la figura de Sócrates aparezca justo en el aforismo que precede a la primera formulación de la experiencia abismal del eterno retorno. De igual manera, no parece ser coincidencia el hecho de que algunos de los capítulos de su autorretrato recuerden a la Apología de Sócrates. Kaufmann insiste: Ecce homo es la apología de Nietzsche ${ }^{40}$.

El reiterado énfasis sobre la figura de Sócrates que recorre lo largo y ancho del Nietzsche de Kaufmann es un tanto cuestionable, entre otras cosas, porque el tratamiento del sabio ateniense no es el mismo en toda la obra de Nietzsche. Baste con señalar que el «Sócrates artístico» no es mencionado en sus últimos textos. No es precipitado pensar que esa posibilidad tan llamativa en Die Geburt der Tragödie se esfuma a medida que madura su pensamiento. Es más, el

35. Ibid., p. 328

36. Ibid., p. 407.

37. W. Kaufmann, «Editor's Introduction», en Ecce Homo, ed. de W. Kaufmann, New York: Vintage, 1969 p. 204.

38. W. Kaufmann, Nietzsche: Philosopher, Psychologist, Antichrist, cit., p. 395.

39. KGW II/4 354.

40. W. Kaufmann, Nietzsche: Philosopher, Psychologist, Antichrist, cit., p. 409. 
parágrafo dedicado a Sócrates en su Götzen-Dämmerung parece agudizar las críticas hacia él. Lo cierto es que la interpretación que avanza Kaufmann sobre la relación entre Sócrates y Nietzsche parece esconder su propia admiración por el primero. Esa afinidad no ha de sorprender a aquél que haya ojeado el prólogo de Tragedy and Philosophy, pues ahí Kaufmann admite «ser un discípulo del Sócrates sarcástico» ${ }^{41}$. Con todo, su Nietzsche sigue siendo una monografía de lectura obligada para cualquier estudioso interesado en la obra y vida del pensador alemán. Sirva lo dicho como una cálida invitación a la lectura de este estimulante libro.

41. W. Kaufmann, Tragedy and Philosophy, cit., p. xxi. 